\title{
Training to reduce LGBTQ-related bias among medical, nursing, and dental students and providers: a systematic review
}

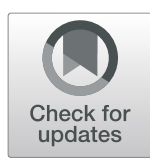

\author{
Matthew Morris ${ }^{1 *}$, Robert Lyle Cooper ${ }^{1}$, Aramandla Ramesh², Mohammad Tabatabai ${ }^{3}$, Thomas A. Arcury ${ }^{4}$, \\ Marybeth Shinn ${ }^{5}$, Wansoo Im $^{1}$, Paul Juarez ${ }^{1}$ and Patricia Matthews-Juarez ${ }^{1}$
}

\begin{abstract}
Background: Lesbian, gay, bisexual, transgender and questioning (LGBTQ) individuals experience higher rates of health disparities. These disparities may be driven, in part, by biases of medical providers encountered in health care settings. Little is known about how medical, nursing, or dental students are trained to identify and reduce the effects of their own biases toward LGBTQ individuals. Therefore, a systematic review was conducted to determine the effectiveness of programs to reduce health care student or provider bias towards these LGBTQ patients.

Methods: The authors performed searches of online databases (MEDLINE/PubMed, PsycINFO, Web of Science, Scopus, Ingenta, Science Direct, and Google Scholar) for original articles, published in English, between March 2005 and February 2017, describing intervention studies focused on reducing health care student or provider bias towards LGBTQ individuals. Data extracted included sample characteristics (i.e., medical, nursing, or dental students or providers), study design (i.e., pre-post intervention tests, qualitative), program format, program target (i.e., knowledge, comfort level, attitudes, implicit bias), and relevant outcomes. Study quality was assessed using a five-point scale.

Results: The search identified 639 abstracts addressing bias among medical, nursing, and dental students or providers; from these abstracts, 60 articles were identified as medical education programs to reduce bias; of these articles, 13 described programs to reduce bias towards LGBTQ patients. Bias-focused educational interventions were effective at increasing knowledge of LGBTQ health care issues. Experiential learning interventions were effective at increasing comfort levels working with LGBTQ patients. Intergroup contact was effective at promoting more tolerant attitudes toward LGBTQ patients. Despite promising support for bias education in increasing knowledge and comfort levels among medical, nursing, and dental students or providers towards LGBTQ persons, this systematic review did not identify any interventions that assessed changes in implicit bias among students or providers.
\end{abstract}

Conclusions: Strategies for assessing and mitigating implicit bias towards LGBTQ patients are discussed and recommendations for medical, nursing, and dental school curricula are presented.

Keywords: Implicit bias, Cultural competence, Medical education, LGBTQ

\footnotetext{
*Correspondence: mmorris5@umc.edu

${ }^{1}$ Department of Family and Community Medicine, Meharry Medical College,

1005 Dr. D. B. Todd Jr. Boulevard, Nashville, TN 37208, USA

Full list of author information is available at the end of the article
}

C The Author(s). 2019 Open Access This article is distributed under the terms of the Creative Commons Attribution 4.0 International License (http://creativecommons.org/licenses/by/4.0/), which permits unrestricted use, distribution, and reproduction in any medium, provided you give appropriate credit to the original author(s) and the source, provide a link to the Creative Commons license, and indicate if changes were made. The Creative Commons Public Domain Dedication waiver (http://creativecommons.org/publicdomain/zero/1.0/) applies to the data made available in this article, unless otherwise stated. 


\section{Background}

Lesbian, gay, bisexual, transgender and questioning (LGBTQ) individuals represent a rapidly growing segment of the U.S. population [1]. This rapid growth brings with it risk for stigmatization [1]. Implicit physician biases may result in LGBTQ patients receiving a lower standard of care or restricted access to services as compared to the general population [2]. Even when institutions and providers make commitments to equitable care explicit, implicit biases operating outside of conscious awareness may undermine that commitment. There is an urgent need to ensure that health care providers are prepared to identify and address their own implicit biases to ensure they do not contribute to the health care disparities experienced by LGBTQ and other vulnerable populations.

LGBTQ individuals face significant disparities in physical and mental health outcomes [3]. Compared to their heterosexual counterparts, LGBTQ patients have higher rates of anal cancer [4], asthma, cardiovascular disease [5-8], obesity [6], substance abuse [8-10], cigarette smoking [11], and suicide [12]. Sexual minority women report fewer lifetime Pap tests [13-15], transgender youth have less access to health care [16], and LGBTQ individuals are more likely to delay or avoid necessary medical care [17] compared to heterosexual individuals. These disparities are due, in part, to lower health care utilization by LGBTQ individuals [3, 18-20]. Perceived discrimination from health care providers and denial of health care altogether are common experiences among LGBTQ patients and have been identified as contributing factors to health disparities [21-24]. Disparities in health care access and outcomes experienced by LGBTQ patients are compounded by vulnerabilities linked to racial identity [25-27] and geographic location [28].

Biases among health care professions students and providers toward LGBTQ patients are common [29, 30] despite commitments to patient care equality. These biases, also known as negative stereotypes, may be either explicit or implicit [31]. A large study of heterosexual, first-year medical students demonstrated that about half of students reported having negative attitudes towards lesbian and gay people (i.e., explicit bias) and over $80 \%$ exhibited more negative evaluations of lesbian and gay people compared to heterosexual people that were outside of their conscious awareness (i.e., implicit bias) [29]. Research in social-cognitive psychology on intergroup processes defines explicit biases as attitudes and beliefs that are consciously-accessible and controlled; they are typically assessed via self-report measures and are limited by an individual's awareness of their attitudes, motivation to reveal these attitudes, and ability to accurately report these attitudes [32, 33]. In contrast, the term implicit bias refers to attitudes and beliefs that are unconscious (i.e., outside of conscious awareness) and automatic [34, 35].
Implicit bias can be assessed with the Implicit Association Test (IAT) [36], which measures the strength of association between concepts [37].

Health care provider biases are correlated with poorer access to services, quality of care, and health outcomes [31, 38-40]. Explicit biases held by health professionals towards racial/ethnic minorities, women, and older adults are known to affect clinical assessments, medical treatment, and quality of care [41]. Importantly, implicit bias measures are more strongly associated with real-world behaviors than explicit bias measures [42] and are linked to intergroup discrimination [43]. Health care provider's implicit biases towards vulnerable patient groups may persist despite an absence of negative explicit attitudes [44], resulting in preconceived notions about patient adherence, poor doctorpatient communication, and micro-aggressions, all of which can interfere with optimal care. With less time and limited information processing capacity, provider's decisions are increasingly governed by stereotypes and implicit biases $[45,46]$. Medical student and provider biases may contribute to health disparities in vulnerable populations by negatively impacting communication with patients and decisions about patient care [33, 35]. Taken together, these findings suggest that medical students and healthcare providers are likely to underestimate or to be unaware of their implicit biases towards LGBTQ patients, particularly when they are rushed or fatigued, which could impact their behavior and judgments in ways that contribute to health disparities experienced by LGBTQ populations.

Theoretical models of bias reduction note that implicit biases are "learned over time through repeated personal experiences and cultural socialization" and are "highly resistant to change" [31, 33]. According to the prejudice habit-breaking framework, overcoming the "habit" of implicit bias "requires learning about the contexts that activate the bias and how to replace the biased responses with responses that reflect one's nonprejudiced goals" [47]. Long-term reductions in implicit racial bias have been achieved through an intervention promoting bias awareness (i.e., feedback following the IAT) and brief training in bias reduction strategies (i.e., stereotype replacement, counter-stereotypic imaging, individuation, perspective-taking, increasing opportunities for intergroup contact) [47]. A meta-analysis of LGBTQ-related bias reduction programs conducted with primarily undergraduate students found large, positive program effects on knowledge and moderate effects on explicit biases toward LGBTQ individuals. Programs providing education, promoting contact with LGBTQ individuals, and/or combining education and intergroup contact had the best results; a major limitation was that few studies included implicit bias measures [48]. Another promising study found a medium effect for a program utilizing 
biographical vignettes of LGBTQ exemplars in reducing implicit bias (assessed with the Sexuality IAT) towards LGBTQ persons $[36,49]$. Together, these studies demonstrate that biases, including those targeting LGBTQ individuals, can be modified [50].

One critical gap in the literature is whether training programs incorporated into medical education can help students to become more aware of potential implicit biases toward LGBTQ patients and to develop effective bias reduction skills to combat these biases in medical school, residency, and beyond. To date, research testing the effectiveness of implicit bias reduction strategies among medical students and physician providers has primarily focused on vulnerable racial and ethnic groups [51]. Promising strategies shown to be effective in reducing implicit racial and ethnic biases in medical students include those which seek to increase bias awareness [52], perspective-taking [53], and seeking counter-stereotypic information [54]. A study of 3547 students from 49 U.S. medical schools found that completing a racial IAT as part of formal curricula was associated with decreases in implicit racial bias from the first to last semester of school [52].

The importance of implicit bias as a contributing factor to the health disparities confronting LGBTQ individuals has been highlighted in professional competency objectives generated by the Association of American Medical Colleges Advisory Committee on Sexual Orientation, Gender Identity, and Sex Development [55]. Identified competencies include understanding how implicit LGBTQ-related bias may negatively impact interactions with patients, and developing strategies to mitigate implicit bias in health care settings [55]. Thus, training health care professions students to be aware of and address implicit biases towards LGBTQ and other vulnerable populations provides a critical opportunity for promoting equal access to quality health care and, ultimately, for eliminating health disparities. However, there appears to be a significant divide on the importance of addressing implicit biases between those in the educational and practice environments. In a survey of health care providers, over half expressed discomfort caring for LGBTQ patients [44] and most providers believe that issues related to LGBTQ health should be covered more thoroughly in medical school curricula [23]. National surveys of medical school deans, in contrast, indicate that only two to five curricular hours are spent addressing the health care needs of LGBTQ patients $[56,57]$ with little to no emphasis on bias reduction strategies.

To our knowledge, no systematic reviews have assessed the impact of LGBTQ bias reduction programs on health care professions students or providers. The present study seeks to address this gap by: 1) evaluating the impact of bias reduction programs on key bias outcomes (i.e., knowledge, explicit attitudes, comfort level, and implicit bias) toward
LGBTQ patients; 2) determining the characteristics of successful programs; and 3) translating key findings into recommendations for medical school training curricula. The focus of this review was on studies of LGBTQ-related bias reduction training programs delivered to medical, nursing, or dental students or providers that included either prepost test designs or qualitative assessments.

\section{Method}

This systematic review of the literature was conducted using PRISMA guidelines [58] to identify original studies that focused on reducing health professions student or provider biases towards LGBTQ individuals.

\section{Search strategy}

An electronic search was conducted in MEDLINE/ PubMed, PsycINFO, Web of Science, Scopus, Ingenta, Science Direct, and Google Scholar databases for articles in English published between March 2005 and February 2017. The search strategy cross-referenced keywords for LGBTQ populations (lesbian, gay, bisexual, transgender, questioning, homosexual, men who have sex with men, MSM, women who have sex with women, WSW, sexual minority); and keywords for health care professions students or providers (provider, physician, doctor, nurse, medical student, medical resident, dental student, health personnel, practitioner, fellow); and keywords for bias (bias, implicit bias, explicit bias, debiasing, cultural competence, cultural competency, discrimination, prejudice, stereotype; stigma; health disparity). An example of the search strategy used in MEDLINE/ PubMed is shown in Fig. 1.

\section{Eligibility criteria and study selection}

The initial search strategy was developed and implemented by two study authors (MCM, AR). To be included in this systematic review, a study had to: 1) assess LGBTQ-related bias; 2) include medical, nursing, or dental students or practicing health care professionals; 3) include a training program designed to promote culturally-competent care for LGBTQ individuals; 4) be written in English; and 5) be published between March 2005 and February 2017. We did not exclude qualitative studies, studies without comparison groups, nor studies conducted outside of North America. A flow diagram of this literature search is presented in Fig. 2.

\section{Data extraction}

The following data were extracted from all studies: sample (i.e., medical, nursing, or dental students or health care providers); program format (e.g., readings lectures, small group discussions, patient panels or interviews); program targets (i.e., knowledge, comfort level, attitudes, implicit bias); summary of key findings regarding program 
Search $((((((" 2005 / 03 / 01 "[D a t e-C r e a t e] ~: ~ " 2017 / 02 / 01 "[D a t e ~-~ C r e a t e]))$

AND (lesbian[Text Word] OR gay[Text Word] OR bisexual[Text Word] OR transgender[Text Word] OR questioning[Text Word] OR homosexual[Text Word] OR MSM[Text Word] OR "men who have sex with men"[Text Word] OR WSW[Text Word] OR "women who have sex with women"[Text Word] OR "sexual minority"[Text Word])))

AND (provider OR physician OR doctor OR nurse OR medical student OR medical resident OR dental student OR health personnel OR practitioner OR fellow)))

AND (bias OR "implicit bias" OR "explicit bias" OR debiasing OR "cultural competence" OR "cultural competency" OR discrimination OR prejudice OR stereotype OR stigma OR "health disparity")

Fig. 1 Example of search strategy applied in MEDLINE/PubMed

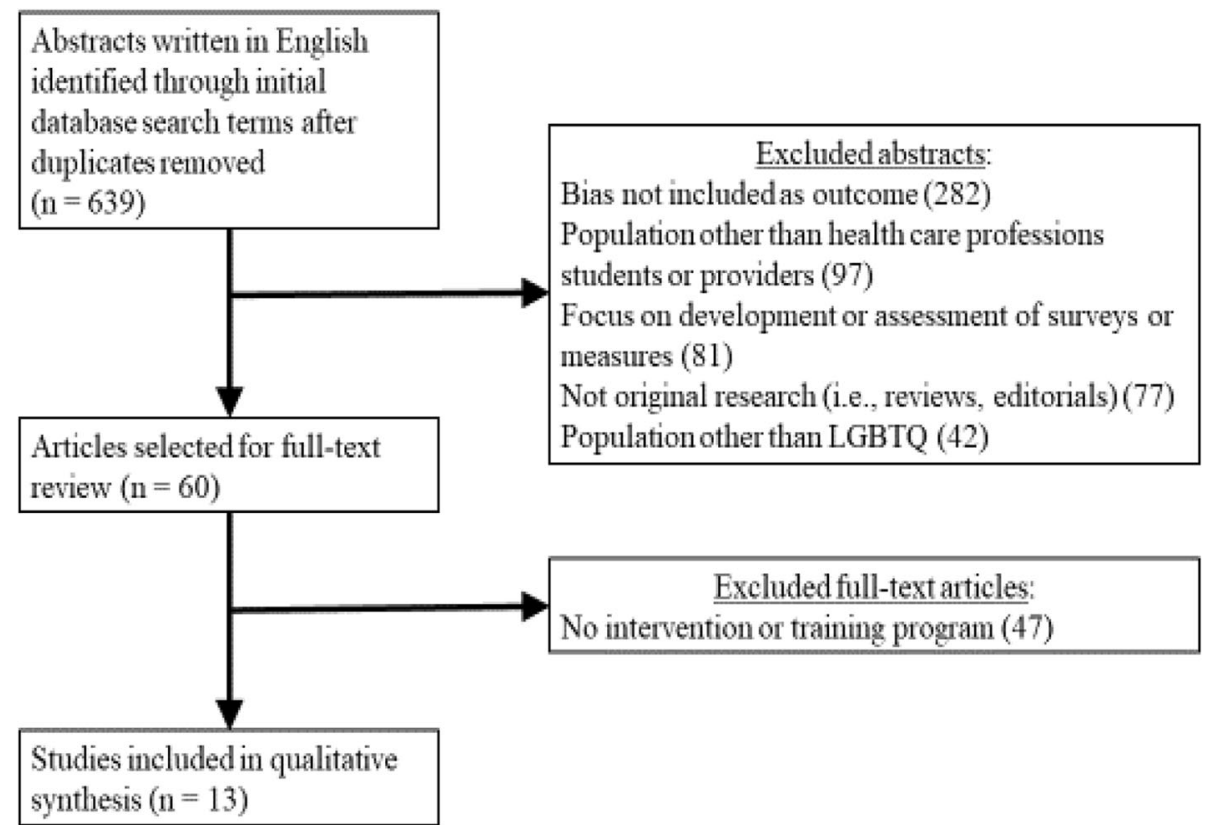

Fig. 2 Flowchart of study selection 
effectiveness. One study author (MCM) extracted data from each study.

\section{Quality assessment}

Methodological quality for all studies was determined by one author (AR). Ratings were made on a scale from 1 (low quality) to 5 (high quality) according to published recommendations [59]. Ratings were based on a consideration of how well the study was designed to address its research questions, the fidelity of implementation, the appropriateness of statistical analyses, and potential threats to validity. Whereas a rating of 5 indicates unequivocal results and is generally reserved for randomized controlled trials, ratings of 1 or 2 are given for study findings that are uninterpretable or ambiguous. Studies were not excluded from the review based on quality ratings; instead, their threats to validity were discussed.

\section{Data analysis and synthesis}

The search and selection process yielded a small number of studies representing a variety of intervention strategies implemented in different groups of health professions students and providers. Heterogeneity in sample characteristics and research designs across studies precluded a quantitative synthesis of the literature. Therefore, the present study provided a qualitative synthesis of the training components that were associated with decreases in LGBTQ-related biases across studies.

\section{Results}

The present study involved a systematic review of training programs that sought to reduce implicit LGBTQ-related bias among health care professions students and providers by improving knowledge about LGBTQ health care, attitudes toward LGBTQ patients, and comfort levels working with LGBTQ patients. The initial search identified 639 abstracts written in English and published between March 2005 and February 2017, after duplicates were removed. During the second stage of the study selection process, these 639 abstracts were screened by one author (MCM) and excluded if they did not include a measure of bias as an outcome $(n=282)$, focused on a population other than health care professions students or providers $(n=97)$, focused on the development or assessment of a survey or measure $(n=81)$, did not report on original research $(n=77)$, or focused on a population other than LGBTQ patients $(n=42)$. During the third stage of the study selection, the remaining 60 full-text articles were assessed for eligibility by two of the authors (MCM, AR), with disagreements resolved by consensus. This resulted in 47 articles being excluded due to the absence of an intervention or training program. Thus, a total of 13 studies were included in the systematic review; of these 13 studies, 9 assessed training programs to reduce LGBTQ-related bias in health care professions students and 4 focused on health care providers.

\section{Study characteristics}

Descriptive information for these studies is provided in Table 1. Sample sizes for these studies ranged from small $(n=13)$ to large $(n=848)$ and included participants representing a wide range of health professions disciplines including medical $(n=6)$ [61, 62, 64-66, 68], nursing $(n=2)[60,67]$ and dental students $(n=1)$ [63] as well as health care providers $(n=4)$ [69-72]. The programs varied in their delivery format (e.g., lecture, small group discussion, interactive theater workshop), frequency (range: 1 to 6 sessions) and duration (range: 45-min lecture to 4-week web-based course). The majority of programs employed a quasi-experimental design involving pre- and post-tests administered to the same audience $(n=12)$ [61-63, 65] 89; one study included qualitative analysis of writing assignments [63]. The 13 programs targeted knowledge $(n=11)$ [60-62, 64-68, 70-72], attitudes $(n=10)$ [61-70] and comfort level $(n=5)$ [60, 61, 66, 71, 72] of medical, nursing, or dental students or providers. Notable limitations of these programs were as follows: none utilized quantitative assessment of implicit bias; none measured changes in student or provider behaviors toward patients; none employed randomized controlled designs; few included outcome measures with established validity and reliability; none included long-term follow-up assessment to determine knowledge retention, improved attitudes, or increased comfort levels (one study included a 3-month follow-up) [64].

\section{Quality ratings of included studies}

Study quality ratings for 8 studies fell within the moderate-to-high range. The remaining 5 studies all received ratings of 2, indicating low quality and elevated risk of bias. The most common threats to validity were high risk of selection bias, small sample sizes, absence of control groups, and research designs lacking validated outcome measures and appropriate statistical analyses.

\section{Impact of interventions on knowledge}

Programs designed to increase student or provider knowledge of the LGBTQ community and LGBTQ-relevant health care issues utilized lectures, readings, videos, interviews or presentations by LGBTQ individuals, and group discussions. They addressed a variety of topics including sexual orientation, gender identity, sexual history taking, LGBTQ terminology, disclosure of orientation and gender identity, discrimination and prejudice toward LGBTQ individuals, impact of LGBTQ-related discrimination on health, factors affecting medical access and care for LGBTQ patients, myths and stereotypes about LGBTQ 


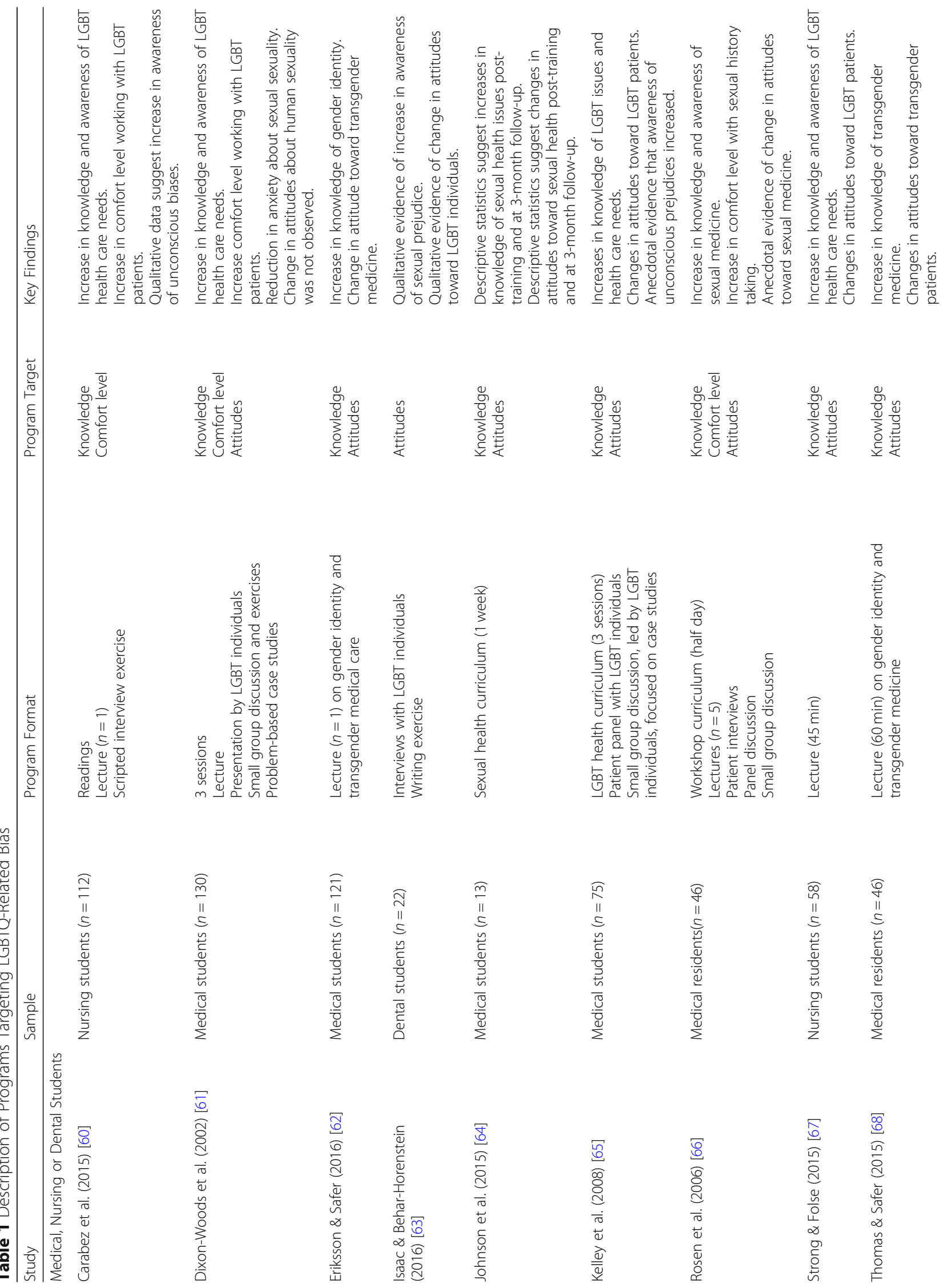




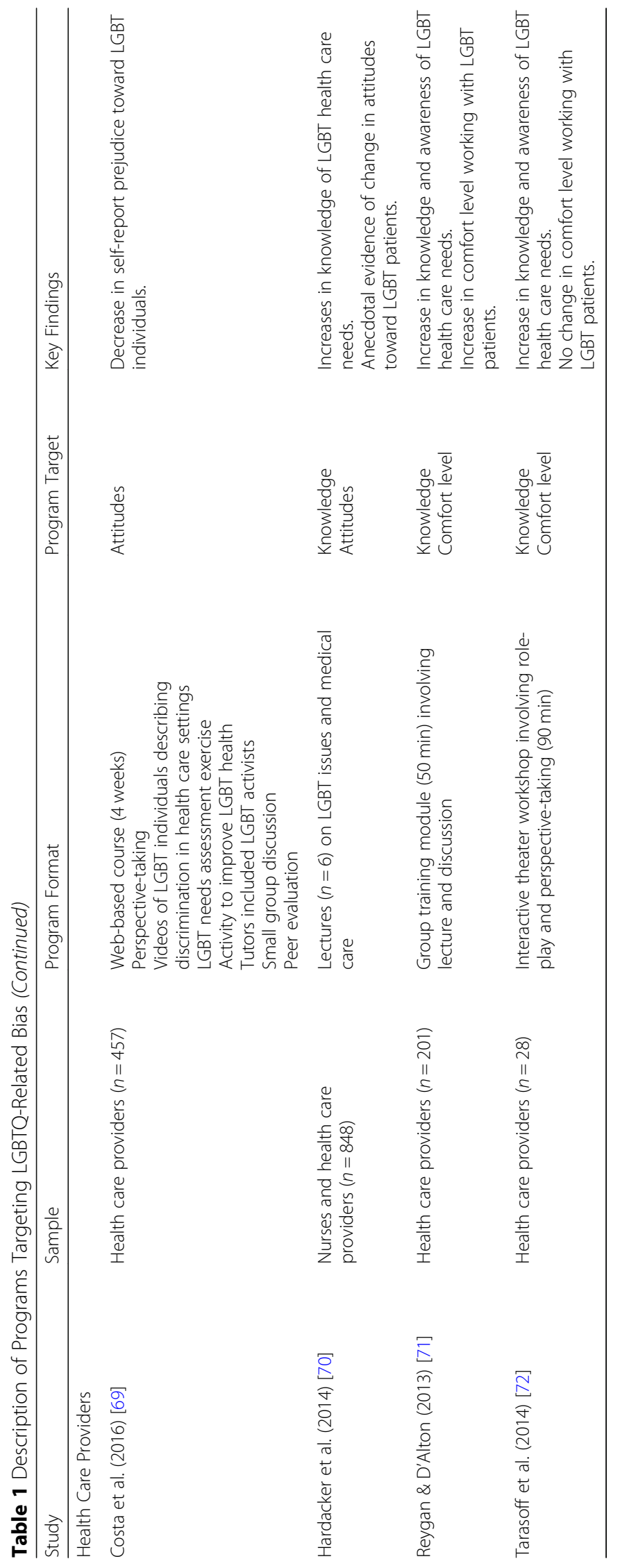




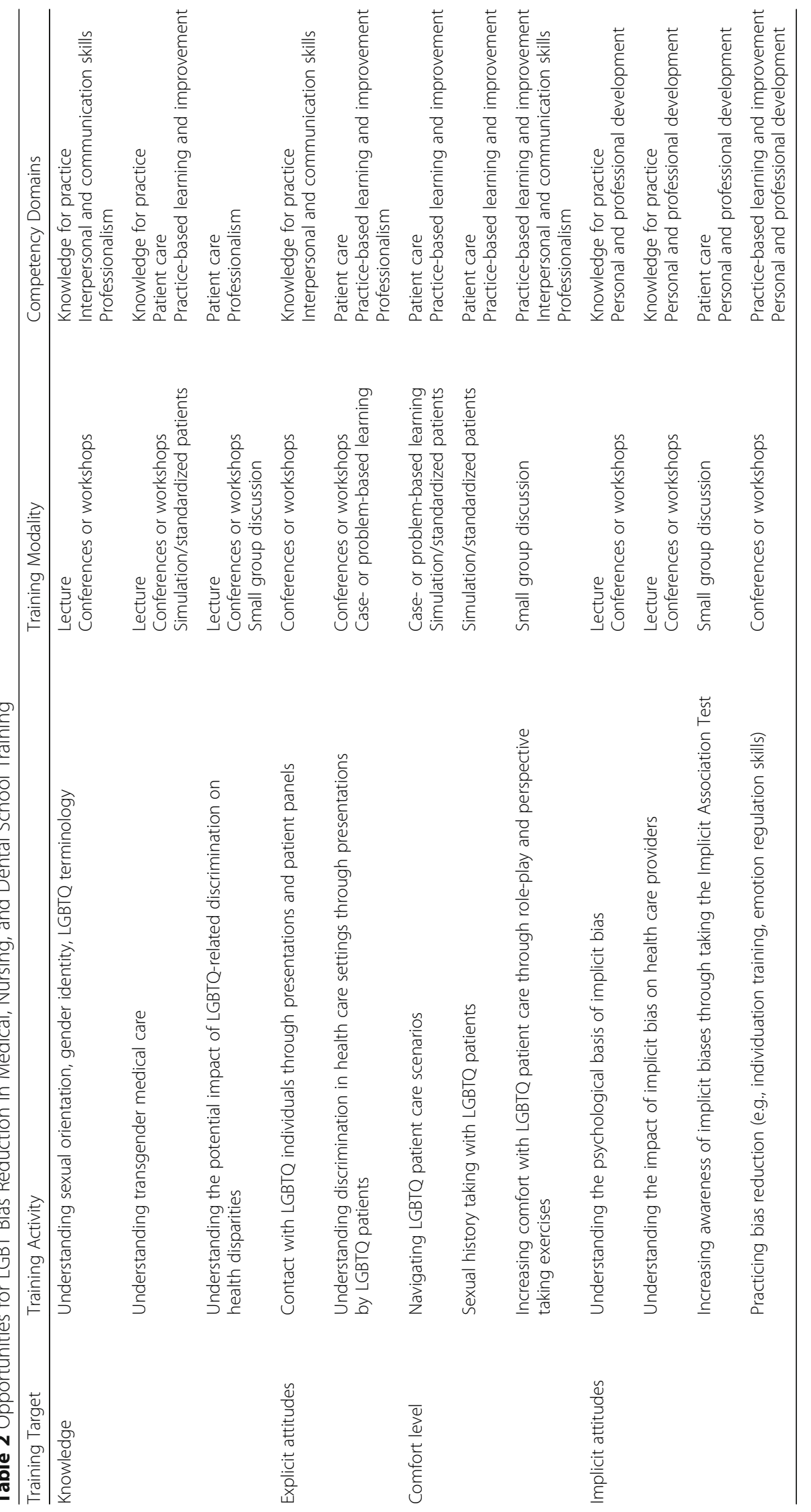


individuals, transgender medical care, and legal concerns relevant to elderly LGBTQ individuals. Knowledge gains were typically assessed using non-standardized measures designed by researchers specifically for their training programs that employed multiple-choice, Likert-scale, or true-false formats; however, one study used items drawn from the Knowledge About Homosexuality Questionnaire [67]. Pre-test findings revealed critical gaps in students' knowledge regarding LGBTQ health care [60]. Overall, programs resulted in significant increases in knowledge for both students and providers representing a variety of disciplines. Significant knowledge gains were observed for students attending single-session programs $[60,62,67,68]$ and for students and providers attending more time-intensive program formats $[64,70]$. The only study assessing knowledge retention found that knowledge gains for medical students were maintained 3 months after the training program [64].

\section{Impact of interventions on attitudes}

Programs designed to promote more positive student or provider attitudes toward LGBTQ patients utilized perspective-taking exercises, videos of LGBTQ patients describing discrimination in health care settings, presentations and patient panels including LGBTQ individuals, and lectures. Changes in attitudes were assessed using the Prejudice Against Sexual and Gender Diversity Scale [69], Attitudes Toward Lesbians and Gay Men Scale [67], an adaptation of the Index of Attitudes toward Homosexuals [65], questionnaires developed specifically for each training program $[61,62,64,66]$, writing exercises on cultural values [63], and interviews with LGBTQ individuals [63].

Overall, training program effects on LGBTQ-related attitudes were inconsistent for health care professions students and providers. Whereas some studies showed significant and positive changes in attitudes toward LGBTQ patients [65, 67-69], other studies found only anecdotal evidence of positive attitude changes [67, 71], or no evidence of changes in attitudes [61]. One study of medical students reported that changes in attitudes continued to be observed at a 3-month follow-up assessment [64]. One component that distinguished effective training programs was the involvement of LGBTQ individuals as tutors or in patient panels $[65,69]$. Although changes in implicit bias were not assessed by quantitative measures, anecdotal evidence from two studies suggested increased awareness of implicit bias among students $[61,66]$. Researchers highlighted the challenge of measuring changes in implicit bias as an important issue to be addressed by future studies [70].

\section{Impact of interventions on comfort level}

Programs designed to increase student or health care provider comfort level working with LGBTQ patients utilized scripted interview exercises, training in sexual history taking, small group discussions, role-play, and perspective-taking exercises [60, 61, 66, 71, 72]. Overall, training programs resulted in increased comfort levels and decreased anxiety levels among health care professions students and providers $[60,61,66,71]$, though one study of health care providers reported no significant changes in comfort [72]. Of note, all of the studies that were effective in increasing comfort levels included group discussions and/or opportunities to practice interviewing skills. None of the studies examined the durability of program-related changes in comfort levels with follow-up assessments.

\section{Discussion}

The effectiveness of intergroup contact as a strategy for reducing prejudice in the general population has been previously documented, with particularly strong effects for LGBTQ-related bias [73]. Our review found that: 1) educational programs can be effective at increasing student and provider knowledge about the LGBTQ community and LGBTQ-related health care; 2) medical and other health care professions students' and providers' comfort levels regarding LGBTQ health care were increased through experiential learning [74]; and 3) intergroup contact is effective at promoting more tolerant attitudes toward LGBTQ patients. Overall, results of this systematic review highlight: the promise of educational programs for knowledge gains; the importance of targeting attitude change in training programs; the need for LGBTQ individuals to be included in discussions with health care professions students and providers; and rehearsal of relevant skills as a strategy to increase comfort levels. Yet, despite promising anecdotal evidence for programs increasing students' awareness of implicit bias $[60,65]$, the bulk of this research has not assessed changes in students' implicit bias towards LGBTQ patients or other vulnerable populations nor have they assessed program-related changes in patient outcomes.

\section{Implications for medical, nursing, and dental school training}

The need for a curricular framework to address implicit bias among health care professions students towards LGBTQ patients is supported by this review. The present findings suggest that training activities and modalities that increase knowledge and comfort level and change attitudes about LGBTQ patients provide effective strategies that can be readily adopted into medical, nursing, and dental school curricula and show promise for reducing disparities.

A blueprint for opportunities to introduce implicit bias reduction training into medical, nursing, and dental school curricula derived from research on implicit bias 
training modalities in the general population is presented in Table 2. Recommendations are made for connecting training activities to: 1 ) training targets (knowledge, explicit attitudes, comfort level, implicit attitudes); 2) training modalities (i.e., lecture, conferences or workshops, caseor problem-based learning, small group discussion, simulation/standardized patients, patient care experiences); and 3) education core competencies (e.g., patient care, knowledge for practice, practice-based learning and improvement, interpersonal and communication skills, professionalism, personal and professional development) [55].

The first step towards successfully reducing implicit bias among health care professions students is to build motivation for change through increasing knowledge among faculty and students for the need for bias awareness. This can be achieved by providing information regarding disparities in health care and the role of health care provider bias, encouraging students to reflect on what they should do in hypothetical encounters with LGBTQ patients and other vulnerable populations, and including strategies designed to reveal implicit biases relevant to LGBTQ individuals [31, 75]. Second, bias awareness strategies should be practiced in a supportive and individualized learning environment such as patient simulation that provides students with opportunities to receive direct feedback about perceived implicit biases while minimizing student defensiveness [33]. Third, curricula should emphasize that implicit biases - whether negative or positive - are universal psychological phenomena [76].

Once implicit biases have been identified, medical students can be taught strategies to minimize their impact and influence on patient care [33], such as perspectivetaking and intergroup contact to promote more positive explicit attitudes and greater comfort working with LGBTQ and other vulnerable patients. Strategies that have received support for reducing implicit bias in other populations include: the use of mindfulness meditation to promote nonjudgmental awareness [77, 78]; individuation training to encourage providers to focus on individual attributes rather than group membership [79]; and training in emotion regulation skills to reduce stress levels and negative emotions [31, 77]. Future studies and medical school training programs should examine the influence of training on implicit LGBTQ-related bias with the Sexuality IAT [36] and/or clinical vignettes presenting scenarios in which characters differ only in group membership [37].

Transforming medical, nursing, and dental education to include implicit bias training is likely to increase students' comfort levels in disclosing their sexual orientation and gender identity to colleagues. Research suggests that LGBTQ medical students and providers frequently conceal their status from colleagues [80], which, in turn, limits opportunities for the very intergroup contact that has been shown to reduce implicit bias [81]. Thus, incorporating LGBTQ-related bias reduction training into medical, nursing, and dental education has the potential to change the "hidden curriculum" [82] within these academic health centers and wherever students go on to practice medicine. In this manner, efforts to reduce implicit bias at the individual level through bias awareness and reduction strategies will be augmented by shifts in institutional climates that are reflected in greater numbers of LGBTQ health care professionals who feel free to openly disclose their identity in the workplace.

\section{Limitations}

Limitations of the present review provide directions for future research. First, study findings are limited in that they do not directly address the impact of training on students' implicit bias or on patient outcomes. Hence, we draw from the extant literature on implicit racial/ethnic bias reduction to generate recommendations for training to address implicit bias towards LGBTQ persons and other vulnerable populations [31, 33, 76]. Second, studies included in this systematic review were not designed to address questions regarding the timing and dosage of debiasing programs. Third, studies have demonstrated a decline in student empathy during medical school [83-85]; hence, researchers have recommended that training programs be repeated [31]. With the exception of one study [64], however, retention of change arising from training was not examined through follow-up assessments. Fourth, the small number of training programs and inconsistent reporting of descriptive statistics for pre- and post-testing (i.e., means and standard deviations) precluded the use of meta-analysis and the assessment of biases across studies. Fifth, five of the included studies were given low quality ratings due to the absence of well-validated outcome measures, risk of selection bias, and small sample sizes. Finally, no studies examined the impact of LGBTQ-related bias training on health care professions student or provider performance or on patient satisfaction. Determining the extent to which attempts to reduce implicit biases and stereotypes have a positive impact on medical, nursing, and dental decision-making and patient interactions is a critical component of program evaluation [86].

\section{Conclusion}

This systematic review addressed a critical gap in the literature on effective strategies to reduce the adverse effects of implicit bias among medical and other health professions students and providers working with LGBTQ populations. Effective strategies that were identified included those that increased knowledge about the health care needs of LGBTQ persons, promoted positive attitudes toward LGBTQ patients, and increased comfort working 
with LGBTQ patients. The present review provides direction for researchers and educators seeking to reduce explicit and implicit bias toward LGBTQ patients among health care professions students and provides and offers a blueprint that can be used to train students on how to become aware of and mitigate their personal biases. Strategies that reduce biases in students and providers are critical steps towards increasing access to care by LGBTQ populations and reducing health disparities.

\section{Abbreviations}

IAT: Implicit Association Test; LGBTQ: Lesbian, gay, bisexual, transgender and questioning; PRISMA: Preferred Reporting Items for Systematic Reviews and Meta-Analyses

\section{Acknowledgements}

The authors wish to acknowledge Dr. Eszter Volgyi for her helpful comments and feedback on the manuscript.

\section{Authors' contributions}

RLC, MCM, TAA, MS, WI, PJ, and PMJ contributed to the conception and design of the systematic review. MCM, AR, and MT conducted the systematic review. All authors were involved in drafting and revising the manuscript. All authors read and approved the final manuscript.

\section{Funding}

This project is supported by the Health Resources and Services Administration (HRSA) of the U.S. Department of Health and Human Services (HHS) under grant number UH1HP30348, entitled "Academic Units for Primary Care Training and Enhancement." This information or content and conclusions are those of the authors and should not be construed as the official position or policy of, nor should any endorsements be inferred by HRSA, HHS or the U.S. Government.

\section{Availability of data and materials}

Data sharing is not applicable to this article as no datasets were generated or analyzed during this qualitative review.

Ethics approval and consent to participate

Not applicable

\section{Consent for publication}

Not applicable

\section{Competing interests}

The authors declare that they have no competing interests.

\section{Author details}

'Department of Family and Community Medicine, Meharry Medical College, 1005 Dr. D. B. Todd Jr. Boulevard, Nashville, TN 37208, USA. ${ }^{2}$ Department of Biochemistry Cancer Biology Neuroscience \& Pharmacology, Meharry Medical College, Nashville, TN, USA. ${ }^{3}$ School of Graduate Studies and Research, Meharry Medical College, Nashville, TN, USA. ${ }^{4}$ Department of Family and Community Medicine, Wake Forest School of Medicine, Winston-Salem, NC, USA. ${ }^{5}$ Department of Human and Organizational Development, Vanderbilt University, Nashville, TN, USA.

Received: 23 May 2018 Accepted: 24 July 2019

Published online: 30 August 2019

\section{References}

1. Waisel DB. Vulnerable populations in healthcare. Curr Opin Anesthesiol. 2013;26(2):186-92.

2. Freid VM, Bernstein AB, Bush MA. Multiple chronic conditions among adults aged 45 and over: Trends over the past 10 years. NCHS Data Brief. 2012; 2012(100):1-8.

3. Institute of Medicine. Collecting sexual orientation and gender identity data in electronic health records: workshop summary. Washington DC: National Academy of Sciences; 2013.
4. Quinn GP, Sanchez JA, Sutton SK, Vadaparampil ST, Nguyen GT, Green BL, et al. Cancer and lesbian, gay, bisexual, transgender/transsexual, and queer/ questioning (LGBTQ) populations. CA-Cancer J Clin. 2015;65(5):384-400.

5. Conron KJ, Mimiaga MJ, Landers SJ. A population-based study of sexual orientation identity and gender differences in adult health. Am J Public Health. 2010;100(10):1953-60.

6. Dilley JA, Simmons KW, Boysun MJ, Pizacani BA, Stark MJ. Demonstrating the importance and feasibility of including sexual orientation in public health surveys: health disparities in the Pacific northwest. Am J Public Health. 2010;100(3):460-7.

7. Fredriksen-Goldsen KI, Kim HJ, Barkan SE, Muraco A, Hoy-Ellis CP. Health disparities among lesbian, gay, and bisexual older adults: results from a population-based study. Am J Public Health. 2013;103(10):1802-9.

8. Bauermeister J, Eaton L, Stephenson R. A multilevel analysis of neighborhood socioeconomic disadvantage and transactional sex with casual partners among Young men who have sex with men living in metro Detroit. Behav Med. 2016;42(3):197-204.

9. Smalley KB, Warren JC, Barefoot KN. Differences in health risk behaviors across understudied LGBT subgroups. Health Psychol. 2016;35(2):103-14.

10. Staats C, Capatosto K, Wright RA, Jackson WW. State of the science: Implicit bias review 2016. Columbus: Kirwan Institute.

11. Cochran SD, Bandiera FC, Mays VM. Sexual orientation-related differences in tobacco use and secondhand smoke exposure among US adults aged 20 to 59 years: 2003-2010 National Health and nutrition examination surveys. Am J Public Health. 2013;103(10):1837-44.

12. Remafedi G, French S, Story M, Resnick MD, Blum R. The relationship between suicide risk and sexual orientation: results of a population-based study. Am J Public Health. 1998;88(1):57-60.

13. Charlton BM, Corliss HL, Missmer SA, Frazier AL, Rosario M, Kahn JA, et al. Reproductive health screening disparities and sexual orientation in a cohort study of U.S. adolescent and Young adult females. J Adolesc Health. 2011; 49(5):505-10.

14. Matthews AK, Brandenburg DL, Johnson TP, Hughes TL. Correlates of underutilization of gynecological cancer screening among lesbian and heterosexual women. Prev Med. 2004;38(1):105-13.

15. Tracy JK, Lydecker AD, Ireland L. Barriers to cervical Cancer screening among lesbians. J Women's Health. 2010;19(2):229-37.

16. Grossman AH, D'Augelli AR. Transgender youth: invisible and vulnerable. Homosex. 2006;51(1):111-28.

17. Krehely J. How to close the LGBT health disparities gap. Center for American Progress; 2009. p. 1-9.

18. Buchmueller T, Carpenter CS. Disparities in health insurance coverage, access, and outcomes for individuals in same-sex versus different-sex relationships, 2000-2007. Am J Public Health. 2010;100(3):489-95.

19. Heck JE, Sell RL, Gorin SS. Health care access among individuals involved in same-sex relationships. Am J Public Health. 2006;96(6):1111-8.

20. Kamen C, Palesh O, Gerry AA, Andrykowski MA, Heckler C, Mohile S, et al. Disparities in health risk behavior and psychological distress among gay versus heterosexual male Cancer survivors. LGBT Health. 2014;1 (2):86-U103.

21. Legal L. When health care Isn't caring: lambda Legal's survey of discrimination against LGBT people and people with HIV. New York: Lamba Legal; 2010.

22. Grant JM, Mottet LA, Tanis J. National Transgender Discrimination Survey Report on health and health care. Washington DC: National Center for Transgender Equality and National Gay and Lesbian Task Force; 2010.

23. Shires DA, Jaffee K. Factors associated with health care discrimination experiences among a National Sample of female-to-male transgender individuals. Health Soc Work. 2015;40(2):134-41.

24. Eliason MJ, Dibble SL, Robertson PA. Lesbian, gay, bisexual, and transgender (LGBT) physicians' experiences in the workplace. J Homosex. 2011;58(10):1355-71.

25. Sullivan PS, Rosenberg ES, Sanchez TH, Kelley CF, Luisi N, Cooper HL, et al. Explaining racial disparities in HIV incidence in black and white men who have sex with men in Atlanta, GA: a prospective observational cohort study. Ann Epidemiol. 2015;25(6):445-54.

26. Millett GA, Peterson JL, Flores SA, Hart TA, Jeffries WL, Wilson PA, et al. Comparisons of disparities and risks of HIV infection in black and other men who have sex with men in Canada, UK, and USA: a meta-analysis. Lancet. 2012;380(9839):341-8.

27. Mereish EH, Bradford JB. Intersecting identities and substance use problems: sexual orientation, gender, race, and lifetime substance use problems. J Stud Alcohol Drugs. 2014;75(1):179-88. 
28. Torres CG, Renfrew M, Kenst K, Tan-McGrory A, Betancourt JR, Lopez L. Improving transgender health by building safe clinical environments that promote existing resilience: results from a qualitative analysis of providers. BMC Pediatr. 2015;15:187.

29. Burke SE, Dovidio JF, Przedworski JM, Hardeman RR, Perry SP, Phelan SM, et al. Do contact and empathy mitigate Bias against gay and lesbian people among heterosexual first-year medical students? A report from the medical student CHANGE study. Acad Med. 2015;90(5):645-51.

30. Sabin JA, Riskind RG, Nosek BA. Health care Providers' implicit and explicit attitudes toward lesbian women and gay men. Am J Public Health. 2015; 105(9):1831-41.

31. Burgess D, van Ryn M, Dovidio J, Saha S. Reducing racial bias among health care providers: lessons from social-cognitive psychology. J Gen Intern Med. 2007;22(6):882-7

32. Wilson TD, Brekke N. Mental contamination and mental correction: unwanted influences on judgments and evaluation. Psychol Bull. 1994; 116(1):117-42.

33. Zestcott CA, Blair IV, Stone J. Examining the presence, consequences, and reduction of implicit Bias in health care: a narrative review. Group Proccess Interg. 2016;19(4):528-42.

34. Greenwald AG, Banaji MR. Implicit social cognition: attitudes, self-esteem, and stereotypes. Psychol Rev. 1995;102(1):4-27.

35. van Ryn M, Saha S. Exploring unconscious bias in disparities research and medical education. JAMA. 2011;306(9):995-6.

36. Greenwald AG, McGhee DE, Schwartz JLK. Measuring individual differences in implicit cognition: the implicit association test. J Pers Soc Psychol. 1998; 74(6):1464-80.

37. Nosek BA, Riskind RG. Policy implications of implicit social cognition. Soc Issue Policy Rev. 2012;6(1):113-47.

38. FitzGerald C, Hurst S. Implicit bias in healthcare professionals: a systematic review. BMC Med Ethics. 2017;18(1):19.

39. Shavers VL, Fagan $\mathrm{P}$, Jones D, Klein WMP, Boyington J, Moten $\mathrm{C}$, et al. The state of research on racial/ethnic discrimination in the receipt of health care. Am J Public Health. 2012;102(5):953-66.

40. Chapman EN, Kaatz A, Carnes M. Physicians and implicit Bias: how doctors may unwittingly perpetuate health care disparities. J Gen Intern Med. 2013; 28(11):1504-10.

41. Committee on Understanding and Eliminating Racial and Ethnic Disparities in Health Care. Unequal treatment: Confronting racial and ethnic disparities in health care. Brian D. Smedley, Adrienne Y. Stith, and Alan R. Nelson, Editors; Committee on Understanding and Eliminating Racial and Ethnic Disparities in Health Care; Board on Health Sciences Policy; Institute of Medicine. Washington, DC; 2003.

42. Greenwald AG, Poehlman TA, Uhlmann EL, Banaji MR. Understanding and using the implicit association test: III. Meta-analysis of predictive validity. J Pers Soc Psychol. 2009;97(1):17-41.

43. Greenwald AG, Banaji MR, Nosek BA. Statistically small effects of the implicit association test can have societally large effects. J Pers Soc Psychol. 2015; 108(4):553-61.

44. Khan A, Plummer D, Hussain R, Minichiello V. Does physician bias affect the quality of care they deliver? Evidence in the care of sexually transmitted infections. Sex Transm Infect. 2008;84(2):150-1.

45. Blair IV, Havranek EP, Price DW, Hanratty R, Fairclough DL, Farley T, et al. Assessment of biases against Latinos and African Americans among primary care providers and community members. Am J Public Health. 2013;103(1):92-8.

46. Rowniak SR. Factors related to homophobia among nursing students. J Homosex. 2015;62(9):1228-40.

47. Devine PG, Forscher PS, Austin AJ, Cox WTL. Long-term reduction in implicit race Bais: a prejudice habit-breaking intervention. J Exp Soc Psychol. 2012; 48:1267-78.

48. Bartos SE, Berger I, Hegarty P. Interventions to reduce sexual prejudice: a study-space analysis and meta-analytic review. J Sex Res. 2014;51(4):363-82.

49. Nosek BA, Smyth FL, Hansen JJ, Devos T, Lindner NM, Ranganath KA, et al. Pervasiveness and correlates of implicit attitudes and stereotypes. Eur Rev Soc Psychol. 2007;18:36-88

50. Dasgupta N, Greenwald AG. On the malleability of automatic attitudes: combating automatic prejudice with images of admired and disliked individuals. J Pers Soc Psychol. 2001;81(5):800-14.

51. Forscher PS, Mitamura C, Dix EL, Cox WTL, Devine PG. Breaking the prejudice habit: mechanisms, timecourse, and longevity. J Exp Soc Psychol. 2017;72:133-46.
52. van Ryn M, Hardeman R, Phelan SM, Burgess DJ, Dovidio JF, Herrin J, et al Medical school experiences associated with change in implicit racial Bias among 3547 students: a medical student CHANGES study report. J Gen Intern Med. 2015;30(12):1748-56.

53. Blatt B, LeLacheur SF, Galinsky AD, Simmens SJ, Greenberg L. Does perspective-taking increase patient satisfaction in medical encounters? Acad Med. 2010;85(9):1445-52.

54. Stone J, Moskowitz GB, Zestcott CA. A brief, active learning workshop for reducing implicit bias among medical students. Manuscript in preparation; 2017.

55. AAMC Advisory Committee on Sexual Orientation Gl, and Sex Development,. Implementing Curricular and Institutional Climate Changes to Improve Health Care for Individuals Who Are LGBT, Gender Nonconforming, or Born with DSD: A Resource for Medical Educators 2014.

56. Kitts RL. Barriers to optimal care between physicians and lesbian, gay, bisexual, transgender, and questioning adolescent patients. J Homosex. 2010;57(6):730-47.

57. Obedin-Maliver J, Goldsmith ES, Stewart L, White W, Tran E, Brenman S, et al. Lesbian, gay, bisexual, and transgender-related content in undergraduate medical education. JAMA. 2011;306(9):971-7.

58. Moher D, Liberati A, Tetzlaff J, Altman DG. PRISMA group. Preferred reporting items for systematic reviews and meta-analyses: the PRISMA statement. Ann Intern Med. 2009;151(4):264-W64.

59. Hammick M, Dornan T, Steinert Y. Conducting a best evidence systematic review. Part 1: from idea to data coding. BEME guide no. 13. Med Teach. 2010;32(1):3-15.

60. Carabez R, Pellegrini M, Mankovitz A, Eliason MJ, Dariotis WM. Nursing students' perceptions of their knowledge of lesbian, gay, bisexual, and transgender issues: effectiveness of a multi-purpose assignment in a public health nursing class. J Nurs Educ. 2015;54(1):50-3.

61. Dixon-Woods M, Regan J, Robertson N, Young B, Cordle C, Tobin M. Teaching and learning about human sexuality in undergraduate medical education. Med Educ. 2002;36(5):432-40.

62. Eriksson SE, Safer JD. Evidence-based curricular content improves student knowledge and changes attitudes towards transgender medicine. Endocr Prac. 2016;22(7):837-41.

63. Isaac C, Behar-Horenstein L. Impact of interviews on heterosexual Students' expressions of cultural competency. Qual Rep. 2016;21(10):1785-98.

64. Johnson K, Rullo J, Faubion S. Student-initiated sexual health selective as a curricular tool. Sexual Med-UK. 2015;3(2):118-27.

65. Kelley L, Chou CL, Dibble SL, Robertson PA. A critical intervention in lesbian, gay, bisexual, and transgender health: knowledge and attitude outcomes among second-year medical students. Teach Learn Med. 2008;20(3):248-53.

66. Rosen R, Kountz D, Post-Zwicker T, Leiblum S, Wiegel M. Sexual communication skills in residency training: the Robert wood Johnson model. J Sexual Med. 2006;3(1):37-46.

67. Strong KL, Folse VN. Assessing undergraduate nursing students' knowledge, attitudes, and cultural competence in caring for lesbian, gay, bisexual, and transgender patients. J Nurs Educ. 2015;54(1):45-9.

68. Thomas DD, Safer JD. A simple intervention raised resident-physician willingness to assist transgender patients seeking hormone therapy. Endocr. 2015;21(10):1134-42.

69. Costa $A B$, Pase PF, de Camargo ES, Guaranha C, Caetano AH, Kveller D, et al. Effectiveness of a multidimensional web-based intervention program to change Brazilian health practitioners' attitudes toward the lesbian, gay, bisexual and transgender population. J Health Psychol. 2016;21(3):356-68.

70. Hardacker CT, Rubinstein B, Hotton A, Houlberg M. Adding silver to the rainbow: the development of the nurses' health education about LGBT elders (HEALE) cultural competency curriculum. J Nursing Manage. 2014; 22(2):257-66.

71. Reygan FC, D'Alton P. A pilot training programme for health and social care professionals providing oncological and palliative care to lesbian, gay and bisexual patients in Ireland. Psychooncology. 2013;22(5):1050-4.

72. Tarasoff LA, Epstein R, Green DC, Anderson S, Ross LE. Using interactive theatre to help fertility providers better understand sexual and gender minority patients. Medical Humanit. 2014;40(2):135-41.

73. Pettigrew TF, Tropp LR. A meta-analytic test of intergroup contact theory. J Pers Soc Psychol. 2006;90(5):751-83.

74. Turner RN, Crisp RJ, Lambert E. Imagining intergroup contact can improve intergroup attitudes. Group Process Intergroup Relat. 2007; 10(4):427-41. 
75. Dasgupta N, Rivera LM. When social context matters: the influence of longterm contact and short-term exposure to admired outgroup members on implicit attitudes and behavioral intentions. Soc Cogn. 2008;26(1):112-23.

76. Staats C, Capatosto K, Wright RA, Jackson WW. State of the science: implicit bias review. 2016th ed. Colubus: Kirwan Institute for the Study of race and ethnicity, The Ohio Statee University.

77. Lueke A, Gibson B. Mindfulness meditation reduces implicit age and race Bias: the role of reduced automaticity of responding. Soc Psychol Personal Sci. 2015;6(3):284-91.

78. Stell AJ, Farsides T. Brief loving-kindness meditation reduces racial bias, mediated by positive other-regarding emotions. Motiv Emot. 2016;40(1): $140-7$.

79. Stone J, Moskowitz GB. Non-conscious bias in medical decision making: what can be done to reduce it? Med Educ. 2011;45(8):768-76.

80. Lee KP, Kelz RR, Dubé B, Morris JB. Attitude and perceptions of the other underrepresented minority in surgery. J Surg Educ. 2014;71:e47-52.

81. Fallin-Bennett K. Implicit bias against sexual minorities in medicine: cycles of professional influence and the role of the hidden curriculum. Acad Med. 2015;90:645-51.

82. Hafferty FW. Beyond curriculum reform: confronting medicine's hidden curriculum. Acad Med. 1998;73:403-7.

83. Bellini LM, Shea JA. Mood change and empathy decline persist during three years of internal medicine training. Acad Med. 2005;80(2):164-7.

84. Bellini LM, Baime M, Shea JA. Variation of mood and empathy during internship. JAMA. 2002;287(23):3143-6.

85. Hojat M, Mangione S, Nasca TJ, Rattner S, Erdmann JB, Gonnella JS, et al. An empirical study of decline in empathy in medical school. Med Educ. 2004; 38(9):934-41.

86. Dovidio JF, Fiske ST. Under the radar: how unexamined biases in decisionmaking processes in clinical interactions can contribute to health care disparities. Am J Pub Health. 2012;102(5):945-52.

\section{Publisher's Note}

Springer Nature remains neutral with regard to jurisdictional claims in published maps and institutional affiliations.

Ready to submit your research? Choose BMC and benefit from:

- fast, convenient online submission

- thorough peer review by experienced researchers in your field

- rapid publication on acceptance

- support for research data, including large and complex data types

- gold Open Access which fosters wider collaboration and increased citations

- maximum visibility for your research: over $100 \mathrm{M}$ website views per year

At $\mathrm{BMC}$, research is always in progress.

Learn more biomedcentral.com/submissions 